\title{
FORMAÇÃO, FUNÇÃO E FORMAS DE PROVIMENTO DO CARGO DO GESTOR ESCOLAR: AS DIRETRIZES DA POLÍTICA EDUCACIONAL E O DESENVOLVIMENTO TEÓRICO DA ADMINISTRAÇÃO ESCOLAR
}

CDD: 379

\author{
FORMATION, FUNCTION AND DESIGN \\ OF CARGO MANAGER PROVISION SCHOOL: \\ GUIDELINES OF THE BRAZILIAN EDUCATIONAL POLICY \\ AND THEORY OF SCHOOL ADMINISTRATION
}

\author{
Graziela Zambão Abdian ${ }^{1}$ \\ Viviani Fernanda Hojas ${ }^{2}$ \\ Maria Eliza Nogueira Oliveira ${ }^{3}$
}

\begin{abstract}
Resumo
O objetivo deste trabalho é, mediante o tensionamento entre as diretrizes da política educacional e o movimento teórico da área, analisar questões históricas e atuais referentes à formação, à função e às formas de provimento do cargo do gestor escolar, entre os anos 1970 e 2000. Para isso, utilizamos entrevistas semiestruturadas realizadas em escolas públicas municipais e estaduais, assim como em uma universidade pública do interior do estado de São Paulo, com integrantes do curso de Pedagogia. Da análise realizada, finalizamos com alguns apontamentos; entre eles, a possibilidade de reacender a discussão, iniciada nos idos dos anos 1960, sobre a necessidade de formação inicial sólida do gestor escolar, para que ele possa exercer a competência pedagógica adquirida e o compromisso político conquistado ao longo desses anos; e interagir de forma crítica e consciente com as diretrizes da política educacional.
\end{abstract}

Palavras-chave: Política educacional. Administração escolar. Gestor escolar.

\begin{abstract}
This work is by tension between the guidelines of educational policy and theoretical movement of the area, analyze historical and current issues relating to the formation, function and ways of filling the office of the school manager, mainly between the years 1970 and 2000. For this, we used semistructured interviews conducted in public schools and state, as well as with members of the Faculty of Education at a public university in the State of São Paulo. The analysis, ending up with some pointers, including the possibility of rekindling the discussion, begun in the late 1960s, the need for robust training school manager so he can carry on teacher competence and gained political commitment won over those years and to interact critically and consciously with the guidelines of educational policy.
\end{abstract}

Keywords: Educational policy. School administration. School manager.

\footnotetext{
${ }^{1}$ Professora Assistente Doutora do Departamento de Administração e Supervisão Escolar e do Programa de PósGraduação em Educação da Universidade Estadual Paulista. E-mail: graziela.maia@gmail.com - Marília, São Paulo, Brasil.

2 Mestre pelo Programa de Pós-Graduação em Educação da Universidade Estadual Paulista. Bolsista da Fundação de Amparo da Pesquisa do Estado de São Paulo (FAPESP). Professora de educação básica. E-mail: vihojas@ hotmail.com - Marília, São Paulo, Brasil.

${ }^{3}$ Doutoranda do Programa de Pós-Graduação em Educação da Universidade Estadual Paulista. Bolsista FAPESP no mestrado e CAPES no doutorado. E-mail: mariaeliza_oliveira@ hotmail.com - Marília, São Paulo, Brasil.
} 


\section{INTRODUÇÃO}

Este artigo é originado de trabalho com dados de pesquisa apoiada pela Fundação de Amparo à Pesquisa do Estado de São Paulo (FAPESP) e vinculada ao Centro de Estudos e Pesquisas em Administração da Educação (CEPAE) ${ }^{4}$, que tem como objetivos principais: a) analisar questões históricas e atuais relacionadas à formação, à função e ao provimento do cargo do gestor escolar e suas possíveis implicações na qualidade de ensino da escola pública; b) problematizar a literatura da área, no que se refere às temáticas articuladas, tensionando-a com as propostas e as práticas de gestão da educação. A pesquisa envolveu vários subprojetos com temáticas integradas ao objetivo principal e utilizou diferentes procedimentos de coleta de dados. Neste artigo, para analisar a categoria formação, trabalhamos com entrevista semiestruturada com integrantes de um curso de Pedagogia de uma universidade pública do interior do estado de São Paulo que passou pelo processo de reestruturação, após a publicação das Diretrizes Curriculares Nacionais (Resolução CNE/CP n 1/2006) (BRASIL, 2006); em relação à função do gestor, entrevistamos diversos diretores e professores de escolas públicas estaduais e municipais; e, relacionada à temática da forma de provimento do cargo do gestor, analisamos todas as provas e os editais para concurso de diretor de escola pública do estado de São Paulo (entre os anos 1970 e 2000), o que, de certa forma, permitirá definir o perfil de gestor desejado pelo governo do estado ou as funções que este atribui àquele.

Portanto, os procedimentos metodológicos utilizados para a construção deste texto envolvem, por um lado, o levantamento, a sistematização e a análise de documentos (provas e editais) e da construção teórica da área de Administração escolar; e, por outro, a realização, a transcrição e a análise de entrevistas semiestruturadas.

Temos o objetivo de trabalhar com esses dados para discutir questões históricas, entre as décadas de 1970 e 2000, presentes na inter-relação entre a formação, a função e a forma de provimento do cargo do gestor escolar, procurando tensionar as diretrizes da política educacional brasileira e, em alguns momentos, as específicas do estado de São Paulo, com o movimento teórico da área. Ao final, indicamos algumas inquietações, sugeridas para debate, advindas da construção coletiva de nosso texto e também das reflexões proporcionadas pelos momentos de diálogo e problematização no CEPAE. O recorte temporal não é apresentado neste texto de forma rígida; sendo assim, permitimo-nos explorar aspectos anteriores ao ano

\footnotetext{
${ }^{4}$ Grupo de Pesquisa, com sede na Faculdade de Filosofia e Ciências - UNESP/Marília, credenciado no CNPq e coordenado pelas docentes Lourdes Marcelino Machado e Graziela Zambão Abdian.
} 
de 1970, porque implicaram em mudanças significativas nos anos posteriores e, quando nos referimos a 2000, exploramos elementos presentes em sua década. Fizemos a opção por este recorte temporal, porque, em relação à categoria formação, os anos de 1970 marcaram a reestruturação do curso de Pedagogia com a instituição das habilitações nas diferentes áreas, inclusive a de Administração escolar; e, nos anos 2000, deu-se a instituição das Diretrizes Curriculares Nacionais para o curso de Pedagogia, que marcam a sua extinção; quanto ao provimento do cargo de diretor de escola, houve, no final da década de 1970, o primeiro processo de seleção desse profissional após a reformulação da estrutura administrativa do sistema de ensino paulista e, nos anos 2000, ocorreu o último concurso promovido pelo estado de São Paulo. Sobre a função do diretor de escola, no final dos anos 1960, houve a publicação dos Cadernos de Administração escolar, que revelam as preocupações com a origem e a consolidação de uma nova área do conhecimento, em discussão desde a constituição da Associação Nacional de Política e Administração da Educação (ANPAE), em 1961; e os anos 2000, assim como indicaremos neste texto, revelam uma pulverização das publicações sobre Administração escolar.

A pesquisa integra o movimento que valoriza não somente a especificidade da escola como também a tem como sujeito mais importante para a realização das pesquisas na área, porque seus integrantes são os reais protagonistas da educação escolar, com seus limites e possibilidades. (NÓVOA, 1995; SILVA JUNIOR, 2002; SILVA JUNIOR; FERRETTI, 2004; LIMA, 2008).

\section{EM PRINCÍPIO: O DIRETOR DE ESCOLA}

No âmbito teórico, as temáticas da formação e da função do administrador escolar não são recentes e foram, de certa maneira, trabalhadas conjuntamente pelos diferentes autores que ofereceram contribuições para a área da Administração escolar.

Teixeira (1968, p. 9-10), um dos fundadores da Associação Nacional de Política e Administração da Educação (ANPAE), atribui semelhanças entre o profissional da saúde e o profissional da educação e defende a excelência no preparo do profissional da educação, assim como é feito no preparo dos profissionais médicos. O autor propõe a formação do administrador escolar em nível de pós-graduação, cabendo ao nível de graduação oferecer cursos de iniciação ou de informação, destinados a familiarizar o professor com aspectos de Administração da escola e do ensino. 
Já para Ribeiro (1968, p. 21-22, grifos do autor), a Administração escolar pode apresentar-se com natureza e função diversas. Como "todo empreendimento humano se estabelece em função de uma filosofia e se desenvolve segundo uma linha política de ação", o administrador escolar não precisa ter sua formação no respectivo serviço de base, ou seja, na docência, uma vez que a Administração escolar é um ramo da Administração geral.

Apesar de distintos subsídios teóricos, os autores profissionalizam a função do diretor, no sentido de defender a importância da formação específica para ocupar tal atividade, o que contribuiu com as preocupações do momento de originar e fazer consolidar uma área de conhecimento específica no Brasil: a Administração escolar.

No âmbito das políticas de formação de educadores, incluindo o diretor de escola, com a Lei $n^{\circ}$ 4.024/1961 (BRASIL, 1961), a formação dos professores para o magistério foi atribuída ao Curso Normal de nível médio, não havendo referência ao curso de Pedagogia. Já em 1962, foi elaborado o Parecer CFE no 251/1962 (BRASIL, 1962), que estabeleceu a primeira regulamentação para o curso de Pedagogia, fixando currículo e duração mínima, com formação do pedagogo generalista, sem a separação entre bacharelado e licenciatura.

No período da ditadura militar, logo após a Lei Federal n 5.540/1968, o Conselho Federal de Educação deliberou mudanças para o curso de Pedagogia por meio do Parecer CFE $n^{\circ}$ 252/1969 (BRASIL, 1969a) e da Resolução CFE nº 02/1969 (BRASIL, 1969b), que introduziram habilitações a serem cursadas após as disciplinas pedagógicas específicas do magistério. O pedagogo encontrou-se dividido entre a identidade de professor e de especialista, sendo que "[...] a maioria dos planos de carreira do magistério alcançou o 'especialista' a um plano mais elevado como profissional da educação.” (BRZEZINSKI, 2007, p. 238, grifo da autora).

Um dos entrevistados, docente - e coordenador, quando o curso ainda apresentava a configuração anterior e passava pela reestruturação, no ano de 2007- do curso de Pedagogia de uma das universidades públicas do estado de São Paulo, revelou que, anteriormente à publicação das Diretrizes Curriculares Nacionais, a separação em habilitações, no curso, era objeto de questionamentos por parte de docentes e alunos. A fala a seguir sugere que, apesar de a Universidade não apresentar os ranços das teorias tecnicistas, havia necessidade de rever a estrutura curricular, diante da mudança de perspectiva de escola: 
Na verdade, a configuração anterior (com as habilitações) revelava isso. Revelava que você podia formar o docente separado do gestor. Então, uma coisa era a formação do docente, outra coisa era a formação do gestor. Quando nós conseguimos trazer a Gestão como um todo - Administração, Supervisão $e$ Orientação educacional - para o corpo do curso, foi uma conquista importante. Porque, de que adianta nós termos um diretor muito bem formado nos princípios da participação democrática, um técnico muito especialista no âmbito da motivação dos participantes, capaz de envolver os seus docentes nas discussões do projeto pedagógico da escola, envolvimento deles para que eles tenham uma visão da escola como um todo, não só da sua turma, não só da sua disciplina, mas tenham isso, etc., ele não vai conseguir isso se esse profissional, na sua formação, não discutiu essas questões da Gestão e da Administração? (DOCENTE DO CURSO DE PEDAGOGIA, 2010).

Com exceção de Teixeira (1968, p. 17), para quem "o administrador escolar não é um capitão, mas um mediador-inovador [...] a tentar coordenar e melhorar um trabalho de equipe de peritos de certo modo mais responsáveis do que ele próprio pelo produto final da escola ou do ensino", parece existir convergência entre as proposições teóricas sobre a função do diretor de escola (ALONSO, 1976; LOURENÇO FILHO, 1963; RIBEIRO, 1968) e as diretrizes de formação deste profissional: especialista a dirigir a escola.

Em termos de cotidiano da escola, em várias entrevistas realizadas com atuais diretores que ocupavam, naquele momento, o cargo de professores das antigas $1^{\mathrm{a}}$ a $4^{\mathrm{a}}$ séries, identificamos falas que condizem com as considerações anteriores. Quando questionada sobre a função do gestor escolar, uma diretora de escola pública municipal, em exercício em 2010, remeteu-se ao passado e assim nos respondeu:

Houve um tempo que chegava um diretor aqui e dizia: daqui para a frente sou o diretor desta escola. A gente não abria a boca para nada. Aquilo era normal. Mas não vejo assim... até não sei como as coisas conseguiam se desenrolar naquele tempo. Mas, a gente, que estava em sala de aula, de repente ... você virava assim e tomava um susto... tinha alguém te vigiando. Existia um controle grande. As coisas eram assim, muito hierárquicas. (DIRETORA ESCOLA MUNICIPAL, 2010).

Em relação à forma de provimento do cargo do diretor, especificamente no estado de São Paulo, Cortina (1999) explica que esse processo inicialmente era realizado com base no Regimento Interno dos Grupos Escolares, Decreto $n^{\circ} 1.253$, de novembro de 1904, o qual previa que a nomeação seria feita pelo governador; e a exigência legal era o diploma da Escola Normal, preferencialmente, ou o diploma da Escola Complementar e dois anos de efetivo exercício em Grupos Escolares ou outro estabelecimento equivalente. Tal procedimento foi alterado com o Decreto n ${ }^{\circ}$ 5.884, de abril de 1933, que instituiu o Código de Educação do Estado de São Paulo, o qual previa concurso de títulos e provas para o 
provimento do cargo de diretor de Grupo Escolar, mantendo a exigência de 400 dias de docência para fins de inscrição ao concurso.

A autora relata que, apesar das tentativas, o concurso não se firmou na rede pública de ensino paulista durante aquela época, pois as práticas políticas clientelistas continuaram transformando a educação em instrumento de favorecimento e aliciamento pessoal. Somente em 1946 foi criado o cargo de diretor de escola em caráter efetivo no estado de São Paulo, e seu acesso "[...] se dava por meio de uma prova que versava sobre cultura geral e especializada e de provas de personalidade" (CORTINA, 1999, p. 65). Mais tarde, ampliaram-se as exigências de formação, podendo efetuar a inscrição no concurso somente os professores primários diplomados pelo Curso de Administradores Escolares ${ }^{5}$ e que tivessem três anos de efetivo exercício no magistério público.

Com a promulgação da Lei Federal no 5.692/1971 (BRASIL, 1971), que fixa as diretrizes e bases para o ensino de $1^{\circ}$ e $2^{\circ}$ graus, os Grupos Escolares foram extintos e, para cumprir o estabelecido nacionalmente, o governo do estado de São Paulo promoveu a reorganização da estrutura física de suas escolas e o remanejamento de pessoal, criando uma nova estrutura, composta por Escolas Estaduais de $1^{\circ}$ Grau, Escolas Estaduais de $2^{\circ}$ Grau, Escolas Estaduais de $1^{\circ}$ e $2^{\circ}$ Graus e Centros Estaduais Interescolares.

O primeiro concurso para provimento do cargo de diretor realizado após esse processo ocorreu no final da década de 1970, e os requisitos indicavam a necessidade de ser portador do diploma do curso de Pedagogia, com habilitação específica em Administração escolar; e de possuir três anos de efetivo exercício na carreira do magistério público estadual até o término das inscrições (SÃO PAULO, 1978). Em relação ao conteúdo dos editais, inicialmente, a preocupação estava voltada para a seleção de um profissional cuja função seria coordenar o trabalho da equipe escolar, garantindo a consecução dos objetivos educacionais e o cumprimento das normas e diretrizes produzidas e determinadas por instâncias superiores, o que, significativamente, vai ao encontro das perspectivas de Administração escolar, que se basearam, quase exclusivamente, na Administração Geral (ALONSO, 1976; RIBEIRO, 1968). A formação do profissional em habilitações que o tornavam especialista se interrelacionava, naquele momento, de forma coerente com as expectativas que se tinha sobre sua

\footnotetext{
${ }^{5}$ O primeiro Curso de Administradores Escolares de São Paulo funcionou no Instituto de Educação "Caetano de Campos", na capital. Posteriormente, esse curso foi sendo instalado nos novos Institutos de Educação criados no estado. A formação de administradores escolares em nível médio foi realizada até o início da década de 1970, pois, nos termos do artigo 30 da Lei Federal nº 5.540/1968 (BRASIL, 1968), o preparo desses profissionais deveria ser realizado em nível superior.
} 
função - garantir a consecução de objetivos preestabelecidos - e, portanto, este perfil delineou-se nos editais para o concurso público, com autores aqui já citados.

O que nos chama a atenção, diante das colocações, é que a Administração escolar, representada naquele momento na figura do diretor, tinha o mesmo sentido a ela atribuído posteriormente por autores progressistas, ou seja, ela era mediação (PARO, 1986). Entretanto, perguntamos: mediação para quê? O contexto estava marcado, sobretudo, por medidas de adequação do sistema educacional ao modelo de desenvolvimento econômico que se intensificava no Brasil e pela necessidade de controle dos objetivos a ser atingidos, o que poderia ser conquistado com uma rígida hierarquia estabelecida no sistema educacional que, consequentemente, se transpôs para as escolas. Assim, em princípio, o diretor de escola pode, sim, ser considerado um "preposto do Estado" (PARO, 1986), para contribuir com o alcance de objetivos previamente delimitados por uma filosofia e uma política fora e acima dele (RIBEIRO, 1968; ALONSO, 1976). Eis, aí, a concepção de qualidade de ensino presente, talvez, de forma uníssona: atingir metas colocadas pelo governo nacional amparado por acordos internacionais (ROMANELLI, 2003).

\section{A TRANSIÇÃO: DO DIRETOR AO GESTOR ESCOLAR}

Até meados da década de 1980, o paradigma da Administração empresarial dominou os estudos em Administração da educação, que tomaram como referência, quase exclusivamente, a Teoria Geral da Administração. Pautada no paradigma da Administração empresarial, a Administração da educação considera que administrar uma escola equivale a administrar uma empresa qualquer, como se a Administração escolar não requeresse nenhuma consideração especial, a não ser, é lógico, levar em conta sua matéria-prima, o aluno (LOURENÇO FILHO, 1963; ALONSO, 1976).

A década de 1980 foi marcada fortemente pela crítica à construção teórica anterior, que assemelhava a escola à empresa e adotava a Teoria Geral da Administração no desenvolvimento teórico da Administração escolar (FÉLIX, 1984; PARO, 1986). O livro de Paro (1986) destaca, entre outros aspectos, a especificidade da Administração escolar como um dos pressupostos para que contribua com o processo de transformação social.

Acompanhando o movimento em curso na comunidade acadêmica, no edital do concurso para provimento do cargo de diretor de escola realizado na rede pública de ensino paulista no final dessa década (SÃO PAULO, 1988), foram indicadas publicações que 
questionam a utilização da perspectiva empresarial como fundamento da prática administrativa realizada nas escolas e apontam a necessidade da reconstrução teórica nessa área (PARO, 1986; SILVA JUNIOR, 1986). Na mesma bibliografia de referência, no entanto, são sugeridos livros nos quais os autores defendem que as teorias administrativas aplicadas principalmente nas empresas podem ser adotadas no cotidiano escolar (HERSEY; BLANCHARD, 1974; ANDRADE, 1979).

Outro aspecto relativo ao conteúdo do edital que merece destaque é a introdução da Lei Complementar $n^{\circ} 444$, de 22 de dezembro de 1985, que dispõe sobre o Estatuto do Magistério Paulista e dá providências correlatas. A referida lei instituiu algumas modificações no que diz respeito à organização do trabalho nas escolas públicas do estado de São Paulo. Dentre as modificações, destaca-se a tentativa de minimizar/diminuir o poder do diretor de escola, mediante a constituição do Conselho de Escola, de caráter deliberativo.

A partir do final da década de 1980, no âmbito nacional das diretrizes da política educacional, também houve a instituição da Gestão democrática da escola pública na Constituição Federal e o crescimento das pesquisas que valorizam a participação e a efetiva democratização da educação, mediante, principalmente, novas formas de organizar o trabalho na escola. A Gestão democrática foi incorporada pela Lei de Diretrizes e Bases da Educação Nacional (Lei n 9394/96) (BRASIL, 1996), principalmente nos artigos 12, 14 e 15, que destacam a necessidade de integração escola-comunidade; a participação dos docentes na elaboração do projeto político-pedagógico e dos pais em órgãos colegiados; e a progressiva autonomia destinada à escola pública de educação básica.

A eleição para diretor, para muitos pesquisadores, trata-se de um ato de democracia e, nesse sentido, passa a ser um dos instrumentos para a vivência da Gestão democrática na escola (MAIA, 2004). Segundo Gadotti (1997), o processo de escolha democrática de diretores escolares foi iniciado na década de 1960 no Rio Grande do Sul, com a eleição para dirigentes baseada em listas tríplices. A partir da década de 1980 até os dias de hoje, tem existido grande preocupação com relação aos processos de escolhas de diretores escolares, o que desencadeia constante questionamento sobre o papel do diretor para a efetivação de uma Gestão democrática em escolas públicas.

A partir de então, há pluralidade de modos para ocupar o cargo de diretor nos diferentes estados e municípios brasileiros, que, juntamente com órgãos colegiados ativos, passam a ser considerados instrumentos para a viabilização da Gestão que se pretende democrática (ROMÃO; PADILHA, 1997), o que foi objeto de pesquisa de diversos 
pesquisadores. Paro (2003, p. 121) contempla a eleição de diretores e traz diversas falas de integrantes de escola de regiões diferentes do País, sendo uma de suas conclusões a de que "a eleição é a forma de escolha de dirigentes escolares mais compatível com a luta por uma escola básica de qualidade e acessível ao maior número de pessoas".

Em relação à formação, apesar de existirem práticas de eleição de diretores sem a exigência da formação na Habilitação em Administração escolar, permanece o curso de Pedagogia constituído dessa forma ${ }^{6}$. Entretanto, esse período foi marcado por fortes discussões, principalmente dos movimentos dos educadores, com a realização da Primeira Conferência Brasileira de Educação, na qual foi criado o Comitê Pró-Participação na Reformulação dos Cursos de Pedagogia e Licenciatura, transformado em Comissão Nacional pela Reformulação dos Cursos de Formação de Educadores (CONARCFE); e, posteriormente, em Associação Nacional pela Formação dos Profissionais da Educação (ANFOPE). As principais defesas foram: a docência como eixo sobre o qual se apoiam a formação do educador e a base comum nacional (SAVIANI, 2007).

Do ponto de vista teórico, fica evidente a mudança de perspectiva nas três categorias apresentadas, ou seja, o movimento dos educadores em busca de uma base comum para formação dos educadores, o que, possivelmente, dispensaria a formação do especialista na forma de habilitações; a mudança de paradigma da Administração escolar; e as discussões sobre a Gestão democrática. Esses aspectos passaram a redefinir, ao menos no campo teórico e legal, a função do diretor. Entretanto, diferentemente do período anterior, parece iniciar de forma explícita um distanciamento (por que não um tensionamento?) entre, de um lado, as pesquisas na área e, de outro, o tom das políticas educacionais em âmbito nacional. Esse distanciamento assemelha-se à polarização realizada por Singer (1996) sobre as visões de educação: por um lado, a civil democrática (teoria da Administração escolar); e, por outro, a produtivista (política educacional).

Vários autores já analisaram o contexto da política educacional do final dos anos 1980 e início dos anos 1990 e criticaram os subsídios que embasaram suas principais diretrizes, mediante, sobretudo, mensuração de resultados objetivos de aprendizagem, com

\footnotetext{
${ }^{6}$ Não é nosso objetivo neste artigo aprofundar os aspectos relacionados à formação do profissional a ser eleito pela comunidade escolar. O assunto pode ser consultado, entre outros autores, em: a) WITTIMANN, L. C.; GRACINDO, R. V. (Org.). O estado da arte em política e gestão da Educação no Brasil (1991-1997). Brasília: Autores Associados, 2001. v. 1.; b) BITTAR, M.; OLIVEIRA, J. F. Gestão e política da educação. Rio de Janeiro, RJ: DPA Editores, 2004.
} 
certa padronização de realidades escolares completamente diferentes ${ }^{7}$. Na perspectiva criticada, o gestor passa a ter fundamental importância, e sua formação passa a ser ainda mais valorizada, principalmente a que adquire em serviço e tendo como construtor do conteúdo o próprio governo federal/estadual ${ }^{8}$. E, nesses cursos, "Gestão democrática", "participação", "tomada de decisão coletiva" são palavras de ordem, assim como na visão mais progressista do movimento da área que, talvez, pudesse se associar à perspectiva civil democrática de que trata Singer (1996).

Assim, podemos dizer que a Administração, agora Gestão ${ }^{9}$, também é mediação. Mas, por um lado, o das diretrizes da política educacional, ela é mediação para o alcance de metas preestabelecidas e condizentes com uma perspectiva, ainda, de racionalidade técnica, muito próxima à dos anos 1970. E porque não dizer que, para isso, ela precisa lançar mão de novas práticas, as mesmas presentes na Administração empresarial, com suas novas "escolas", que também defendem o trabalhador cooperativo, a "decisão coletiva" e a participação, mesmo que possam ser consideradas "autonomia meramente operacional" e/ou "participação controlada?” (BRUNO, 1997). Por outro lado, o do movimento da área, da própria sociedade e dos educadores em geral, ela é mediação para o alcance de objetivos estritamente educacionais, de difícil mensuração, que requerem transparente e lento trabalho coletivo de construção e vivência de cidadania.

Para explicitarmos melhor nossa compreensão de gestão enquanto mediação e instrumento a serviço de determinados objetivos, precisamos, necessariamente, mesmo que de forma breve, destacar o que e como entendemos a educação escolar. A análise aqui efetivada compreende a natureza da educação enquanto trabalho não material, cuja especificidade se encontra nos conhecimentos, nos valores e nas ideias "sob o aspecto de elementos necessários à formação da humanidade em cada indivíduo singular, na forma de uma segunda natureza,

\footnotetext{
${ }^{7}$ O número especial da Educação \& Sociedade de 2005 focaliza a educação básica sob o prisma das políticas públicas de educação (EDUCAÇÃO \& SOCIEDADE, 2005).

${ }^{8}$ Vários trabalhos analisaram estes cursos, entre eles citamos uma pesquisa financiada pela FAPESP que analisou o ProGestão: CALIXTO, E. A. Programa ProGestão: implicações para a formação e prática dos diretores escolares. Trabalho de Conclusão de Curso (Pedagogia). Faculdade de Filosofia e Ciências de Marília (UNESP), 2007.

${ }^{9}$ Alguns autores da Administração escolar discutem a mudança terminológica de Administração para Gestão. Não consideramos que haja diferenças entre os conceitos; por isso, utilizamos como sinônimos. No entanto, destacamos, com Maia (2004) e Silva Junior (2002), que, apesar de não existir diferença conceitual, a alteração não se faz em um vazio histórico; ao contrário, pode representar o retorno da perspectiva empresarial para a escola. Em seus estudos, Maia (2004) indica que os autores que publicaram a Revista Brasileira de Política e Administração da Educação, entre os anos 1980 e 2000, associam gestão à perspectiva democrática e Administração à perspectiva tradicional, centralizadora. O mesmo movimento é perceptível na realidade das escolas públicas de que pudemos participar e em que pudemos entrevistar muitos de seus profissionais.
} 
que se produz deliberada e intencionalmente, através de relações pedagógicas historicamente determinadas que se travam entre os homens" (SAVIANI, 2008, p. 22). Não desconsiderando sua densidade histórica, que traz as marcas das contradições sociais e da função social historicamente posta, concebemos a escola como espaço institucional de produção do saber historicamente produzido pela humanidade, o que indica para ela uma função pedagógica específica e potencial no enriquecimento da sociedade, do ponto de vista humano, político e social. Portanto, apesar de todas as forças contraditórias que possam marcar seu espaço, a escola constitui-se como o local institucional de construção humanizadora do ser social e pode servir tanto a uma "forma de resistência a uma suposta condenação quanto à procura por outros horizontes, mais equânimes, mais emancipatórios” (CURY, 2008, p. 220).

O elemento principal da prática escolar que pode vir a contribuir com esta potencial função é a natureza específica do seu processo pedagógico, que se constitui a partir de três aspectos principais: o papel do educando no processo pedagógico de produção; a natureza do saber envolvido no processo; e, finalmente, o conceito de "produto" da educação escolar (PARO, 1986). No processo pedagógico, o aluno é sujeito, objeto e coprodutor, ou seja, sem sua participação efetiva, o processo não se consubstancia, o que difere sobremaneira da "matéria-prima" da empresa. O saber envolvido em tal processo, o conhecimento historicamente acumulado, é inerente ao processo, portanto, não pode ser desvinculado dos trabalhadores, alunos e professores; já na empresa, ele se restringe às poucas pessoas que, hierarquicamente o detém para benefícios da classe dominante. O último elemento, o produto da educação escolar, ou seja, "o aluno educado", dificilmente pode ser mensurado como se faz na empresa, mediante o lucro das vendas. Ao contrário, o que o aluno leva para sua vida e a forma como esses conhecimentos incidem sobre sua realidade não se pode mensurar.

$\mathrm{Na}$ perspectiva apresentada, pensar sobre a gestão escolar é pensar sobre as condições materiais a partir das quais se desenvolve a ação educativa, e, nesse sentido, a gestão escolar, em seu sentido clássico, apresenta-se como a mediação necessária. Por essa razão, só faz sentido contemplar a atividade administrativa se os fins a que ela servir forem conhecidos e apropriados pela comunidade educativa, porque, se, no sentido geral, a administração é "a utilização racional de recursos para a realização de fins determinados" (PARO, 1986, p. 18), pode-se afirmar que "os objetivos é que condicionam a administração" (PARO, 2007, p. 554).

No entanto, o contexto explicitado anteriormente parece indicar contradições na função do gestor escolar, ao indicar duas perspectivas, com suas diretrizes específicas, que 
são opostas: a da política educacional, que traz, em certa medida, a revitalização dos aspectos empresariais para a escola (inclusive no que tange à liderança do diretor); e a das pesquisas acadêmicas, que analisam as possibilidades e os limites de vivências democráticas e de construção coletiva de fins para a escola pública ${ }^{10}$.

A contradição explicitada faz-se presente, com clareza, nas falas dos diferentes diretores que entrevistamos, de escolas municipais e de escolas estaduais de municípios do interior do estado de São Paulo, nos quais são concursados ou indicados. Há uma unanimidade na incorporação do discurso da Gestão democrática, mas, quando se aproximam do real, aparece o antigo diretor, com características eminentemente técnicas, com foco no controle e na execução de tarefas, por também serem cobrados pelos órgãos centrais. As falas a seguir ilustram nossos apontamentos:

nós temos feito um trabalho democrático, tem hora que é lógico, como as coisas são impostas a gente não pode fugir muito daquilo que vem dos superiores, mas dentro da escola a gente trabalha democraticamente. (DIRETORA DE ESCOLA MUNICIPAL, 2010)

Olha a Administração é o carro chefe. Então a Administração tem que ser uma liderança com uma visão de equipe com a elaboração de todos na participação $e$ não sendo é... egocêntrica, mas a participação de todos é... a parte administrativa é a parte mais importante, mas se ela não for de uma liderança é... solidária participativa não funciona. (DIRETORA DE ESCOLA MUNICIPAL, 2010)

Independentemente das especificidades municipais, a força das diretrizes nacionais parece controlar até mesmo as práticas mais democráticas conquistadas por políticas locais de municípios que quiseram fazer a diferença no que diz respeito à função e à forma de provimento do cargo do gestor escolar. A afirmação encontra respaldo em inúmeras pesquisas já realizadas no Brasil, que também denotam as contradições e os limites da vivência de processos efetivamente democráticos via eleição de diretores e participação da comunidade na Gestão da escola (LUCE; MEDEIROS, 2006).

\footnotetext{
${ }^{10}$ Podemos dizer que as diretrizes da política educacional se respaldam também em pesquisas acadêmicas que, na área da Administração educacional com a perspectiva gerencial (de empresas), indicam termos como eficiência, eficácia e liderança do diretor para a consecução de escolas eficazes. Várias obras podem ser consultadas a esse respeito, entre elas, destacamos: Nóvoa, 1995 e LUCK, H. A escola participativa. O trabalho do gestor escolar. São Paulo, SP: DP\&A, 2000.
} 


\section{OS ANOS 2000: POSSIBILIDADES DE ANALISAR A FORMAÇÃO, A FUNÇÃO E O PROVIMENTO DO CARGO DO GESTOR ESCOLAR E AS DIRETRIZES DA POLÍTICA EDUCACIONAL}

Em 2007, a ANPAE ${ }^{11}$ publicou um número temático sobre formação de professores e o curso de Pedagogia (REVISTA..., 2007), com a intenção de registrar a longa e debatida tramitação da Resolução CNE/CP n 1/2006, que instituiu as Diretrizes Curriculares Nacionais para o curso de Graduação em Pedagogia. O registro desse movimento, que deu origem às DCN vigentes, procura destacar o processo de elaboração de uma série de documentos, publicados a partir de 1970, que apresentaram desde a possibilidade de extinção do Curso de Pedagogia, até seu fortalecimento enquanto responsável pela formação de profissionais da educação aptos para atuarem na docência e nas diversas áreas que envolvem assuntos educacionais.

Ao descrever a trajetória da luta pelas Diretrizes Curriculares, Castro (2007) cita os vários documentos elaborados pelo conjunto de entidades (ANPEd, ANFOPE, ANPAE, FORUNDIR CEDES ${ }^{12}$ e Fórum Nacional em Defesa da Formação de Professores) e afirma que, depois de uma série de negociações com o CNE, aprovou-se a Resolução CNP/CP n. 1, que instituiu as DCN para o Curso de Graduação em Pedagogia. No documento consta que

O Curso de Licenciatura em Pedagogia destina-se à formação de professores para exercer funções de magistério na Educação Infantil e nos anos iniciais do Ensino Fundamental, nos cursos de Ensino Médio, na modalidade Normal, de Educação Profissional na área de serviços e apoio escolar e em outras áreas nas quais sejam previstos conhecimentos pedagógicos. (BRASIL, 2006).

As conquistas parecem articular-se diretamente com o movimento da área da Administração escolar que, mesmo não tendo a preocupação explícita de discutir a formação do diretor/gestor de escola, aponta para a necessidade de qualquer professor poder vir a ser um diretor, desde que eleito por sua comunidade. Em termos nacionais, realizaram-se discussões a respeito da eleição de diretores na Conferência Nacional de Educação, realizada no primeiro semestre de $2010^{13}$, que a estabeleceu como uma das próximas conquistas, em termos de metas, para a escola pública.

\footnotetext{
${ }^{11}$ ANPAE - Associação Nacional de Política e Administração da Educação.

12 ANPEd - Associação Nacional de Pós-Graduação e Pesquisa em Educação, CEDES - Centro de Estudos Educação e Sociedade.

${ }^{13} \mathrm{O}$ documento final da CONAE está disponível em:

〈http://conae.mec.gov.br/images/stories/pdf/pdf/documetos/documento_final_sl.pdf $>$.
} 
No caso do estado de São Paulo, que manteve o concurso como forma de provimento do cargo de diretor, nos editais referentes aos concursos realizados a partir de 2000, a formação específica em Administração Escolar deixou de ser uma exigência para aqueles que tenham concluído o curso de Pedagogia.

Em relação ao perfil profissional, conforme as informações contidas no edital relativo ao concurso realizado no ano de 2007, o diretor de escola, como gestor público, deveria reunir características que lhe possibilitassem: refletir sobre o cotidiano escolar de forma a aprimorá-lo; compreender os condicionamentos políticos e sociais que interferem no cotidiano escolar; propor ações que incorporem as demandas da comunidade local aos propósitos pedagógicos da escola; valorizar a gestão participativa; articular e executar as políticas educacionais; reconhecer a importância das ações de formação continuada para o enriquecimento da prática pedagógica em sala de aula; acompanhar e avaliar o desenvolvimento da proposta pedagógica; compreender os princípios e as diretrizes da administração pública (SÃO PAULO, 2006).

Na bibliografia básica do referido concurso nota-se que as publicações sugeridas, embora apontem a necessidade de repensar a gestão da escola, não constituem estudos substanciais voltados para a teoria administrativa escolar. Os artigos (MACHADO, 2000; SCHNECKENBERG, 2000) e os livros organizados na forma de coletânea (FERREIRA; AGUIAR, 2001; VIEIRA; ALMEIDA; ALONSO, 2003), de um modo geral, discutem questões relacionadas a autonomia, participação, trabalho coletivo e liderança na escola e ressaltam a importância do gestor enquanto agente articulador de mudanças na educação.

Seguindo o raciocínio lógico das décadas anteriores, nas quais os concursos públicos realizados para o cargo de diretor de escola pública refletiram, de certa forma, o movimento da área, talvez possamos afirmar que, neste momento, a produção se caracteriza pela quase ausência de construção de conhecimento novo em Administração escolar, indicada pela quantidade de coletâneas da área listadas nas referências e pela entrada expressiva de autores de outras áreas, principalmente da Administração empresarial, sem interfaces diretas com a educação.

Do exposto, considerando especialmente que não há mais a formação específica inicial para o gestor escolar, quem e como determina, de fato, a função que exerce esse profissional no cotidiano das escolas?

Na realidade educacional de um município do interior do estado de São Paulo, onde os gestores são concursados e muitos são substitutos indicados pela própria secretaria, quando 
questionada sobre a função do gestor, a secretária destacou que "o diretor é o gestor escolar, ele tem que saber o que acontece dentro da escola, porque, além da formação em Pedagogia, ele tem de ter cinco anos de experiência de magistério”. Continua, ao abordar a questão da formação, afirmando que

o diretor é uma das peças principais porque a educação não se faz sozinha e os responsáveis pela educação são todos os integrantes da escola, da merendeira, que sabe sentir as necessidades das crianças quando ela está ali com eles, até o diretor. Mas o diretor que é o responsável por articular todos esses níveis e processos dentro da escola. E, além da competência técnica e política, ele tem que ter a perspicácia de liderança. (SECRETÁRIA, 2010).

E, finaliza: "ele é o líder, ele tem que exercer essa função".

O supervisor pedagógico dessa mesma secretaria indica que "além da Pedagogia, o diretor tem de ter formação constante, oferecemos tudo que pudemos”. E a secretária complementa: "No nosso caso específico, já oferecemos o ProGestão, que foi uma parceria com a Coordenadoria de Normas Pedagógicas (CENP), fizemos também a parceria com o Ministério da Educação, com a Escola de Gestores, curso semipresencial e, fora isso, no cotidiano, esse trabalho com os diretores é focado" ${ }^{\text {"14. }}$.

Diante do exposto, parece transparecer que a repercussão direta na função do gestor é a formação continuada que recebe, pautada, sobretudo, em uma política de educação nacional com rígido controle sobre as especificidades regionais e locais e a supervalorização de aspectos técnicos e mensuráveis que acabam por esvaziar a riqueza do processo pedagógico e da multiplicidade de realidades escolares.

\section{CONCLUSÕES: NOVOS PONTOS PARA DEBATE}

O objetivo deste trabalho foi, mediante tensionamento entre as diretrizes da política educacional e o movimento teórico da área, analisar questões históricas e atuais referentes à formação, à função e a formas de provimento do cargo do gestor escolar, circunscritas, principalmente entre os anos 1970 e 2000. Para isso, utilizamos algumas entrevistas

\footnotetext{
${ }^{14}$ Uma das autoras deste artigo coletou dados sobre a temática aqui contemplada, em uma pesquisa de pós-doutorado realizada em um município do estado do Rio Grande do Sul, no qual os gestores escolares são eleitos pela comunidade. É interessante indicar que, ao entrevistar a secretária do município, pudemos identificar que a percepção sobre a função do profissional é diferente da percepção da secretaria do município do estado de São Paulo, uma vez que aquela destaca, de início, a questão de ser o gestor o representante da comunidade, dos anseios da comunidade. Entretanto, quando falamos sobre a formação, as diretrizes da secretaria se equiparam às do município do interior do estado de São Paulo. Sendo assim, no município paulista, os diretores concursados e alguns substitutos indicados recebem os mesmos cursos de "formação continuada" que os diretores eleitos pela comunidade escolar do município do Rio Grande do Sul.
} 
semiestruturadas que vêm sendo realizadas por diversos integrantes do grupo de pesquisa, em inúmeras escolas públicas municipais e estaduais, assim como com integrantes do curso de Pedagogia de uma universidade pública do interior do estado de São Paulo.

As discussões realizadas nos proporcionam considerar que, entre o final dos anos 1960 e meados dos anos 1980, parece existir movimento convergente das perspectivas teóricas e das diretrizes gerais relacionadas à formação, à função e ao provimento do cargo do “diretor" de escola. Este profissional necessita de formação específica que o constitui como especialista da educação para coordenar, controlar e supervisionar seus subordinados para a consecução de objetivos preestabelecidos fora e acima dele (ou de sua competência). Cabe ressaltar que, apesar de os pesquisadores desse período tomarem como referência a Administração empresarial (Teoria Geral da Administração), apresentam estrita preocupação com os objetivos educacionais. Especificamente no estado de São Paulo, o concurso reflete o perfil do profissional retratado anteriormente, com a bibliografia coerente com o movimento teórico da área, que toma, com exclusividade, a Administração empresarial como subsídio teórico.

Os anos 1980, com o processo de democratização da sociedade, foram marcados por mudança de perspectiva teórica na área e pelo movimento dos educadores, que passaram a reivindicar, entre outros aspectos, a base docente para formação do educador. Em termos de política educacional, há crescente multiplicidade de realidades e práticas de Gestão, principalmente no que se refere à forma de provimento do cargo e à efetivação da participação no interior das organizações escolares. Parece existir um distanciamento entre, de um lado, as diretrizes da política nacional, marcadas, sobretudo, por aspectos economicistas, de controle e prestação de contas; e, de outro, o crescimento do movimento social e da área pela busca da participação efetiva da comunidade nas decisões da escola, mediante, principalmente, eleição de diretores, órgãos colegiados e vivência da Gestão democrática. Neste ínterim, os discursos parecem se confundir e, entre o ideal e o real, a contradição se explicita nas falas dos diretores de escola. No estado de São Paulo, os concursos refletem o momento de mudança na área e também listam, em suas referências, autores que questionam o paradigma empresarial na Administração escolar.

Nos anos 2000, com a publicação das Diretrizes Nacionais para o curso de Pedagogia, as habilitações foram extintas e, com elas, a formação do especialista em educação. O movimento da formação de educadores parece convergir com o movimento específico da área da Administração escolar, que indica, entre outros aspectos, que qualquer 
docente poderá vir a ser gestor, desde que eleito pela comunidade. As diretrizes da política educacional, pensando na formação e na forma de provimento do cargo dos gestores, parecem ir ao encontro das considerações teóricas, mas, simultaneamente, incentivam cursos de formação continuada de gestores escolares (e adquiridos pelas diferentes secretarias estaduais e municipais do País) e estabelecem rígido controle, via avaliação em larga escala, dos resultados de aprendizagem. Nesse sentido, no imaginário dos gestores, está presente a necessidade de desenvolvimento da Gestão democrática, mas, efetivamente, o que se espera dele é que seja um líder “orquestrador de atores" (LUCK, 2000) e capaz de somar esforços para atingir os rankings nacionais.

Talvez por isso, as vivências positivas de Gestão democrática não se multiplicam com intensidade, pois "no âmbito da prática, surgiram modos diversos de reconcentração do poder do diretor, esquemas participativos sutilmente manipulativos, fragmentação, basismos e populismos, para não falar em omissão”. Por que não dizer que houve,

em síntese, uma profusão de comissões, colegiados e conselhos; não importa a denominação que tenham recebido, mas quase todos micro-colegiados discutidores de microproblemas, dando aos seus membros a sensação de participação... quantas vezes ilusória? (MACHADO, 2000, p. 78).

Sem dúvida, a base docente foi uma conquista do ponto de vista da formação do educador, mas nosso questionamento, diante do exposto, é: em que medida as esparsas disciplinas alocadas no curso de Pedagogia proporcionam, ao futuro gestor agora formado como educador, uma visão do complexo sistema educacional tecido no bojo da política internacional e com diretrizes preestabelecidas para as realidades locais? Como esse educador, com forte e densa base docente (pedagógica) e comprometido politicamente com sua comunidade (uma vez eleito) interage com essas determinações? Como ele recebe (receberá) os cursos de formação adquiridos por suas respectivas secretarias?

Pretendemos reacender a discussão, iniciada nos idos dos anos 1960, sobre a necessidade de formação inicial sólida do gestor escolar e, talvez, venhamos a defender, como Teixeira (1968) e os poucos pesquisadores da área da Administração escolar que abordaram a formação deste profissional (MACHADO; MAIA, 2007; WERLE, 1992), a necessidade de formação sólida para ele, mesmo que em nível de pós-graduação. Além dos aspectos abordados, nossa preocupação é a de que a Administração, enquanto participação, não se feche em si mesma, pois, para estar a serviço dos fins, o gestor tem de conhecer por quem e 
como são construídos os fins, a serviço de quem está, seus limites e suas reais possibilidades de atuação.

Não defendemos uma formação que o capacite ao exercício do controle ou do poder autoritário, mas uma formação que lhe proporcione, sobretudo, exercer o compromisso político conquistado e o conhecimento pedagógico adquirido. Para isso, precisamos construir um corpus teórico específico e, "se efetivamente, estivermos preocupados com a construção de um domínio teórico que possa oferecer sustentação autônoma e consistente à prática institucional da Administração escolar, temos que, evidentemente, percorrer outros caminhos.” (SILVA JUNIOR, 2002, p. 2002). As possibilidades reais de construção do conhecimento em Administração escolar encontram-se no cotidiano das organizações educativas, no qual os

actores escolares não se limitam ao cumprimento sistemático e integral das regras hierarquicamente estabelecidas por outrem, não jogam apenas um jogo com regras dadas a priori, jogam-no com a capacidade estratégica de aplicarem selectivamente as regras disponíveis e mesmo de inventarem e construírem novas regras. (LIMA, 2008, p. 93-94, grifos do autor).

\section{REFERÊNCIAS}

ALONSO, Mirtes. O papel do diretor na Administração escolar. São Paulo, SP: Difel, 1976.

ANDRADE, Narcisa Veloso. Administração em educação. Rio de Janeiro, RJ: Livros Técnicos e Científicos , 1979.

BRASIL. Presidência da República. Lei no 4024 de 20 de dezembro de 1961. Fixa as Diretrizes e Bases da Educação Nacional. Disponível em: http://www2.camara.gov.br/legin/fed/lei/19601969/lei-4024-20-dezembro-1961-353722-publicacaooriginal-1-pl.html. Acesso em 03 de março de 2011.

BRASIL. Parecer $n^{\circ}$ 251/62. Currículo mínimo e duração para o curso de graduação em Pedagogia. Relator: Valnir Chagas. Documenta, ${ }^{\circ}$ 11, p. 59-65, 1962.

BRASIL. Congresso Nacional. Lei n ${ }^{\circ}$ 5.540, de 28 de novembro de 1968. Fixa normas de organização e funcionamento do ensino superior e sua articulação com a escola média, e dá outras providências. In: SILVA, C. S. B. da. Curso de Pedagogia no Brasil: história e identidade. $2^{\mathrm{a}}$ Ed. Campinas: Autores Associados, 2003. (Coleção Polêmicas do Nosso Tempo; 66).

BRASIL. Parecer n 252/69. Estudos pedagógicos superiores. Mínimos de conteúdo e duração para o curso de graduação em Pedagogia. Relator: Valnir Chagas.

Documenta, $\mathrm{n}^{\circ} 100$, p. 101-117, 1969a. 
BRASIL. Ministério da Educação. Conselho Federal de Educação. Resolução CFE n 2/69, de 12 de maio de 1969b. Fixa os mínimos de conteúdo e duração do Curso de Pedagogia.

BRASIL. Lei Federal n ${ }^{\circ} 5.692$, de 11 de agosto de 1971. Fixa Diretrizes e Bases para o ensino de $1^{\circ}$ e $2^{\circ}$ graus, e dá outras providências. Disponível em: http://www81.dataprev.gov.br/sislex/paginas/42/1971/5692.htm. Acesso em: 20 de fevereiro de 2011.

BRASIL. Lei n. 9.394, de 20 de dezembro de 1996. Estabelece as diretrizes e bases da educação nacional. Disponível em: 〈http://www.pedagogiaemfoco.pro.br/19394 96.htm〉. Acesso em: 01 de março de 2011.

BRASIL. CONSELHO NACIONAL DE EDUCAÇÃO. Conselho Pleno. Resolução CNE/CP n. 1/2006, de 15 de maio de 2006. Institui Diretrizes Curriculares Nacionais para o Curso de Graduação em Pedagogia, licenciatura. Diário Oficial da União, Brasília, 16 maio 2006.

BRUNO, Lúcia. Poder e administração no capitalismo contemporâneo. In: OLIVEIRA, Dalila Andrade. (Org.). Gestão democrática da educação: desafios contemporâneos. Petrópolis: Vozes, 1997.

BRZEZINSKI, Iria. A formação de professores para a educação básica e o Curso de Pedagogia: a tensão entre o instituído e instituinte. Revista Brasileira de Política e Administração da Educação, Porto Alegre, v. 23, n. 2, p. 229-251, maio/ago. 2007.

CASTRO, Magali de. A formação de professores e gestores para os anos iniciais da educação básica: das origens às diretrizes curriculares nacionais. Revista Brasileira de Política e Administração da Educação, Porto Alegre, v. 23, n. 2, p. 199-227, maio/ago. 2007.

CORTINA, Roseane Leite. Burocracia e educação: o diretor de escola no Estado de São Paulo. Araraquara: FCL/Laboratório Editorial/UNESP; São Paulo: Cultura Acadêmica Editora, 1999.

CURY, Carlos Roberto Jamil. A Educação escolar, a exclusão e seus destinatários. Educação em Revista, Belo Horizonte, n. 48, p. 205-222, dez. 2008.

EDUCAÇÃO \& SOCIEDADE - Revista de Ciência da Educação. Campinas, v. 26, n. 92, p. 7191156, out. 2005. Especial. Disponível em: 〈http://www.cedes.unicamp.br $>$. Acesso em: 02 de fevereiro de 2011.

FELIX, Maria de Fátima Castro. Administração escolar: problema educativo ou empresarial. São Paulo, SP: Cortez, 1984.

FERREIRA, Naura Syria Carapeto; AGUIAR, Marcia Angela da S. (Org.). Gestão da educação: impasses, perspectivas e compromissos. São Paulo, SP: Cortez, 2001.

GADOTTI, Moacyr. Projeto político-pedagógico da escola: fundamentos para sua realização. In: GADOTTI, Moacyr; ROMÃO, José E. (Org.). Autonomia da escola: princípios e propostas. 2. ed. São Paulo, SP: Cortez, 1997. p. 33-41. 
HERSEY, Paul; BLANCHARD, Kenneth. H. Psicologia para administradores de empresas: a utilização de recursos humanos. Trad. Dante Moreira Leite. São Paulo, SP: EPU; Rio de Janeiro, RJ: Fundação Nacional de Material Escolar, 1974.

LIMA, Licínio C. A escola como organização educativa: uma abordagem sociológica. 3. ed. São Paulo, SP: Cortez, 2008.

LOURENÇO FILHO, Manoel Bergstrom. Organização e Administração escolar. São Paulo, SP: Melhoramentos, 1963.

LUCE, Maria Beatriz; MEDEIROS, Isabel Letícia Pedroso. (Org.). Gestão escolar democrática: concepções e vivências. Porto Alegre: UFRGS, 2006. p. 51-63.

LÜCK, Heloísa. Perspectivas da Gestão escolar e implicações quanto à formação de seus gestores. Em Aberto, Brasília, v. 17, n. 72, p. 11-32, 2000.

MACHADO, Lourdes Marcelino. Quem "embala" a escola? Considerações a respeito da gestão da unidade escolar. In: MACHADO, Lourdes Marcelino; MAIA, Graziela Zambão Abdian. (Org.). Administração e supervisão escolar: questões para o novo milênio. Marília: Pioneira, 2000 .

MACHADO, Lourdes Marcelino; MAIA, Graziela Zambão Abdian. A formação dos profissionais da educação à luz das novas diretrizes curriculares nacionais. Revista Brasileira de Política e Administração Escolar, Porto Alegre. v. 23, n. 2, p. 293-313-78, maio/ago. 2007.

MACHADO, Maria Aglaê de Medeiros. Desafios a serem enfrentados na capacitação de gestores escolares. Em Aberto, Brasília, v.17, n.72, p. 97-112, jun. 2000.

MAIA, Graziela Zambão Abdian. As publicações da ANPAE e a trajetória do conhecimento em Administração da Educação no Brasil. 2004. 196 fl. Tese (Doutorado em Educação) Faculdade de Filosofia e Ciências, Universidade Estadual Paulista, Marília, 2004.

NÓVOA, Antonio. (Coord). As organizações escolares em análise. 2. ed. Lisboa: Dom Quixote, Instituto de Inovação Educacional, 1995.

PARO, Vítor. Henrique. Administração escolar: introdução crítica. São Paulo, SP: Cortez, 1986.

Eleição de diretores: a escola experimenta da democracia. $2^{\mathrm{a}}$ ed. SP: Xamã, 2003. . José Querino Ribeiro e o paradoxo da Administração Escolar. Revista Brasileira de Política e Administração da Educação, v. 23, n. 3, p. 561-570, set./dez., 2007.

REVISTA BRASILEIRA DE POLÍTICA E ADMINISTRAÇÃO DA EDUCAÇÃO (RBPAE). Associação Nacional de Política e Administração da Educação. Porto Alegre, v. 23, n. 2, maio/ago. 2007. p.169-408.

RIBEIRO, José Querino. Introdução à Administração Escolar (alguns pontos de vista). In: ANPAE. Administração escolar. Edição Comemorativa do I Simpósio de Administração Escolar, 1968. 
ROMÃO, J. E; PADILHA, P. R. Diretores escolares e Gestão democrática da escola. In:

GADOTTI, Moacyr; ROMÃO, J. E. (Org.). Autonomia da escola: princípios e propostas. 2. ed.

São Paulo, SP: Cortez, 1997. p. 91-102.

ROMANELLI, Otaíza. História da Educação no Brasil. 28. ed. Petrópolis: Vozes, 2003.

SÃO PAULO (ESTADO). Diário Oficial do Estado, São Paulo, 23 de março de 1978. p. 67-68.

SÃO PAULO (ESTADO). Diário Oficial do Estado, São Paulo, 6 de abril de 1988. p.98.

SÃO PAULO (ESTADO). Diário Oficial do Estado, São Paulo, 15 de Março de 2006. p. 14-15.

SAVIANI, Dermeval. Pedagogia: espaço da educação na Universidade. Cadernos de Pesquisa, São Paulo, v. 37, p. 99-134, jan./abr. 2007.

. Pedagogia histórico-crítica: primeiras aproximações. 10. ed. Campinas, SP: Autores

Associados, 2008 (Coleção educação contemporânea).

SCHNECKENBERG, Marisa. A relação entre política pública de reforma educacional e a gestão do cotidiano escolar. Em Aberto, Brasília, v.7, n. 72, p. 113-124, fev./jun. 2000.

SILVA JUNIOR, Celestino Alves. O espaço da administração no tempo da gestão. In:

MACHADO, Lourdes Marcelino; FERREIRA, Naura Syria Carapeto. (Org.). Política e gestão da educação: dois olhares. Rio de Janeiro, RJ: DP\&A, 2002. p. 199-212.

. Organização do trabalho na escola: a prática existente e a teoria necessária. Cadernos de Pesquisa, São Paulo, n. 59, p. 73-76, nov. 1986.

SILVA JUNIOR, João dos Reis; FERRETTI, Celso. J. O institucional, a organização e a cultura da escola. São Paulo, SP: Xamã, 2004.

SINGER, Paul. Poder, política e educação. Revista Brasileira de Educação, Rio de Janeiro, n. 1, p. 1-14, jan. abr. 1996.

TEIXEIRA, Anísio. Natureza e função da administração escolar. Salvador: ANPAE, 1968.

VIEIRA, Alexandre Thomaz; ALMEIDA, Maria Elizabeth Bianconcini de Almeida; ALONSO, Myrtes. (Org.). Gestão educacional e tecnologia. São Paulo, SP: Avercamp, 2003.

WERLE, Flávia Obino Corrêa. Participação da Universidade com os demais níveis de ensino e a formação do educador- novas perspectivas para o administrador da educação. Revista Brasileira de Política e Administração Escolar, Porto Alegre, v. 8, n. 2, p. 79-99, jul./dez. 1992. 